WellBeing International

WBI Studies Repository

3-2016

\title{
Does environmental enrichment promote recovery from stress in rainbow trout?
}

\author{
Kieran C. Pounder \\ University of Liverpool \\ Jennifer L. Mitchell \\ University of Liverpool \\ Jack S. Thomson \\ University of Liverpool \\ Tom G. Pottinger \\ Lancaster Environment Centre \\ Jonathan Buckley \\ University of Liverpool
}

See next page for additional authors

Follow this and additional works at: https://www.wellbeingintlstudiesrepository.org/exprawel

Part of the Animal Experimentation and Research Commons, Animal Studies Commons, and the Bioethics and Medical Ethics Commons

\section{Recommended Citation}

Pounder, K. C., Mitchell, J. L., Thomson, J. S., Pottinger, T. G., Buckley, J., \& Sneddon, L. U. (2016). Does environmental enrichment promote recovery from stress in rainbow trout?. Applied Animal Behaviour Science, 176, 136-142. https://doi.org/10.1016/j.applanim.2016.01.009

This material is brought to you for free and open access by WellBeing International. It has been accepted for inclusion by an authorized administrator of the WBI Studies Repository. For more information, please contact wbisr-info@wellbeingintl.org.

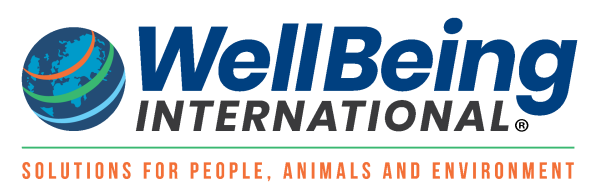


Authors

Kieran C. Pounder, Jennifer L. Mitchell, Jack S. Thomson, Tom G. Pottinger, Jonathan Buckley, and Lynne U. Sneddon 
Article (refereed) - postprint

Pounder, Kieran C.; Mitchell, Jennifer L.; Thomson, Jack S.; Pottinger, Tom G.; Buckley, Jonathan; Sneddon, Lynne U. 2016. Does environmental enrichment promote recovery from stress in rainbow trout?

(C) 2016 Elsevier B.V.

This manuscript version is made available under the CC-BY-NC-ND 4.0 license http://creativecommons.org/licenses/by-nc-nd/4.0/ (cc) EY-NC-ND

This version available http://nora.nerc.ac.uk/511155/

NERC has developed NORA to enable users to access research outputs wholly or partially funded by NERC. Copyright and other rights for material on this site are retained by the rights owners. Users should read the terms and conditions of use of this material at http://nora.nerc.ac.uk/policies.html\#access

NOTICE: this is the author's version of a work that was accepted for publication in Applied Animal Behaviour Science. Changes resulting from the publishing process, such as peer review, editing, corrections, structural formatting, and other quality control mechanisms may not be reflected in this document. Changes may have been made to this work since it was submitted for publication. A definitive version was subsequently published in Applied Animal Behaviour Science (2016), 176. 136-142.

10.1016/j.applanim.2016.01.009

www.elsevier.com/

\section{Contact CEH NORA team at noraceh@ceh.ac.uk}

The NERC and CEH trademarks and logos ('the Trademarks') are registered trademarks of NERC in the UK and other countries, and may not be used without the prior written consent of the Trademark owner. 


\section{Does environmental enrichment promote recovery from stress in rainbow trout?}

Kieran C. Pounder ${ }^{a^{*}}$, Jennifer L. Mitchell ${ }^{\mathrm{a}}$, Jack S. Thomson ${ }^{\mathrm{b}}$, Tom G. Pottinger ${ }^{\mathrm{c}}$, Jonathan Buckley ${ }^{\mathrm{a}}$ \& Lynne U. Sneddona .

anstitute of Integrative Biology, University of Liverpool, Crown Street, Liverpool, L69 7ZB. 6

${ }^{\mathrm{b}}$ School of Environmental Sciences, University of Liverpool, L69 3GP.

${ }^{\mathrm{c} C e n t r e ~ f o r ~ E c o l o g y ~ \& ~ H y d r o l o g y . ~ L a n c a s t e r ~ E n v i r o n m e n t ~ C e n t r e, ~ L i b r a r y ~ A v e n u e, ~ B a i l r i g g, ~}$ Lancaster, LA1 4AP.

*Corresponding author: kpounder@liverpool.ac.uk

Highlights

- We investigated how habitat enrichment may promote welfare of captive rainbow trout

- Environmental enrichment promotes recovery following stressful treatments

- Habitat enrichment may not affect the magnitude of inter-individual variation

- Painful stimulus appeared to override benefits provided by enrichment

- Enrichment should be implemented in experimental studies using rainbow trout 


\begin{abstract}
The EC Directive on animal experimentation suggests that all protected animals should have enrichment to improve welfare yet relatively little research has been conducted on the impact of enrichment in fish. Studies employing enrichment in zebrafish have been contradictory and all fish species should be provided with species-specific enrichments relevant to their ecology. Salmonids are important experimental models in studies within aquaculture, toxicology and natural ecosystems. This study therefore sought to establish whether an enriched environment in an experimental aquarium may promote improved welfare in rainbow trout (Oncorhynchus mykiss) by enhancing their recovery from invasive procedures. Trout were held individually in either barren (no tank ornamentation) or enriched (gravel, plants and an area of cover) conditions. Recovery rates after a noxious stimulus and a standard stressor were investigated by monitoring behaviour, opercular beat rate and plasma cortisol concentrations. Fish were randomly assigned to one of four treatment groups: Control (undisturbed), Sham (handled but not manipulated), Stress (air emersion) and Pain (subcutaneous injection of acetic acid). The results suggest that for rainbow trout environmental enrichment appears to promote recovery and ameliorate adverse effects following a stressor. However, recovery rate did not differ between environments in the pain treatment groups. Thus environmental enrichment may not be an important factor when the fish is responding to a painful stimulus. These results have important implications for the husbandry and welfare of captive rainbow trout and possibly other salmonids and suggest that enriched environments may be preferable to barren environments in experimental studies.
\end{abstract}

Keywords: Oncorhynchus mykiss, environmental enrichment, fish welfare, recovery, stress, intraspecific variation 


\section{Introduction}

There is a plethora of evidence supporting the benefits of enrichment for animals held in captivity, particularly mammals (Simpson and Kelly, 2011; Singhal et al., 2014). However, evidence for the benefits or otherwise of enriched environments for fish is lacking. Fish are a widely exploited research model, second only to mice in numbers used (UK Home Office 2013), but more importantly they also constitute a major source of protein with an estimated two million tonnes of farmed fish being produced across Europe annually (FEAP, 2014). Globally, aquaculture is a growing industry and this growth is inevitably accompanied by concerns about the welfare of intensively-farmed fish employed in research aimed at resolving production problems.

Natural environments are more heterogeneous than those found in captivity and this disparity may result in stress or impaired cognitive function among captive animals with obvious implications for welfare (e.g. Kellison et al., 2000; Brown and Day, 2002; Huntingford, 2004; Sundstrom et al., 2004; Araki et al., 2008). For animals kept in captivity the EU directive on the protection of animals used for scientific purposes (EU Directive 2010) recommends, although does not enforce, that captiveheld fish should be kept in enriched conditions. However, despite this recommendation, relatively little is known about the benefits of enrichment for captive fish and what is required to maintain a high standard of welfare. In captivity for example the habitat often remains non-enriched (from this point onward referred to as barren) with no heterogeneity, for ease of cleaning, removal and transfer of fish, reduction of the spread of disease etc. Whilst there are many different definitions of environmental enrichment, the same general concept applies: increasing environmental complexity within an animal's surroundings that is in some way beneficial to not only maintaining but also improving general animal welfare. Enrichment can be further categorised into areas that target the different aspects of an animal's life; social, diet, cognitive, sensory, and physical (Näslund and Johnsson, 2014). 
The results of research on environmental enrichment in fish are contradictory and highlight the extensive variation between and even within species. As reviewed in Näslund and Johnsson (2014), there are several studies demonstrating the positive effects of environmental enrichment on welfare across many fish species. Compared with captive-held fish in barren environments, those provided with some form of enrichment have been found to have increased brain development (Marchetti and Nevitt, 2003; Kihslinger and Nevitt, 2006; von Krogh et al., 2010; Salvanes et al., 2013), reduced impact from stressors (Braithwaite and Salvanes, 2005; Naslund et al., 2013; Batzina et al., 2014), improved foraging ability (Brown et al., 2003; Strand et al., 2010; Rodewald et al., 2011), improved post-release survival (D'Anna et al., 2012) and positive effects on growth (Leon, 1975; Hansen and Moller, 1985; Batzina et al., 2014). This general increase in neural plasticity results in the development of behaviourally flexible fish that are better at coping with a variety of situations. Although it must be noted that there are also studies demonstrating negative and neutral associations of environmental enrichment (See Näslund and Johnsson, 2014).

As a consequence of the diversity in natural histories exhibited in fish, as well as the wide range of both physiological and behavioural traits, it is likely that the ideal enrichment will have to be judged on a species by species and possibly even on a life stage basis. Here we examine the rainbow trout (Oncorhynchus mykiss), a commercially important salmonid with more than 380,000 tonnes (FEAP, 2014) being produced annually through aquaculture in Europe and as such this species is also widely used in scientific research (Thorgaard et al., 2002) but there remains a paucity of information on enrichment in captivity in this species.

If a lack of environmental enrichment affects fish behaviour, physiology or welfare then this would undoubtedly be a confounding factor when interpreting experimental results and might lead to erroneous conclusions from experiments (Williams et al., 2009; Killen et al., 2013). In laboratory rodent studies, enrichment can improve the health and welfare of the test subjects but may also reduce individual variation such that the data sets are more robust and scientifically valid (Singhal et al., 
2014). The present study was conducted to investigate the effects of simple environmental enrichment on (i) the recovery of rainbow trout from stressors and invasive procedures, and (ii) the degree of interindividual variability among the data collected.

\section{Methods}

\subsection{Fish husbandry}

Experiments were conducted with approval from the Home Office, U.K. (licence no.PPL 40/3435) and the University of Liverpool's Ethics Committee. Juvenile rainbow trout, Oncorhynchus mykiss (average weight $92.48 \pm 2.72 \mathrm{~g} ; n=64$ ), were obtained from a commercial supplier and maintained in stock tanks $(2 \times 2 \times 0.5 \mathrm{~m})$ in a semi-recirculating system at $11 \pm 1{ }^{\circ} \mathrm{C}$, with constant aeration and a 14:10 $\mathrm{h}$ light:dark cycle. The trout were allowed at least two weeks in the stock tanks to recover from the stress of transport. Fish were fed commercial trout diet (Skretting, Northwich, U.K.) at $1 \%$ body weight per day. For experiments, fish were caught at random and transferred individually to separate glass aquaria $(90 \times 50 \times 45 \mathrm{~cm}$ ) with either barren (air stone only) or enriched (air stone, gravel, plastic plant and an overhead area of cover) conditions that were screened from visual disturbance. Tanks were provided with filtered water and aeration by a semi-closed recirculation system; light, temperature and feeding regimes were identical to those of the stock tank. Rainbow trout are a naturally territorial species and form dominance hierarchies where subdominants and subordinates are chronically stressed due to low social status (Gilmour et al., 2005; Sneddon et al., 2011). Therefore, this species is less stressed when held individually where they are allowed to form a "territory" within their holding tank without the stress of social subordination or territorial disputes (e.g. Frost et al., 2007; Thomson et al., 2011; 2012; Frost et al., 2013) thus we tested fish individually to ensure social stress was not a confounding factor and behaviour and physiological responses were consistent over the experimental period and any responses were due to the treatments imposed. 


\subsection{Experimental procedure}

Fish (enriched $n=32$; barren $n=32$ ) remained in individual tanks for at least two weeks until acclimatised and were allowed at least seven days after resumption of feeding. To avoid any biasing, fish were randomly assigned to one of four treatment groups: Control where the fish were left undisturbed; Sham where fish were anaesthetised in benzocaine (Sigma-Aldrich Co., UK) dosed water (0.033 g L-1; Mettam et al., 2012) but no invasive procedure undertaken; Pain where a subcutaneous injection of $1 \%$ acetic acid was administered into the frontal lips $(0.5 \mathrm{ml}$ in each) during anaesthesia; and Stress where fish were subject to one minute of air emersion by holding the fish in a net (Pickering and Pottinger, 1989). All fish were tested at the same time each day to account for diel variations, and treatments were conducted out of view of other subjects. Trout and other fish are commonly exposed to stressors and invasive treatments causing tissue damage that may give rise to pain in laboratory studies (e.g. invasive tagging (Weigel et al., 2014), vaccination (Bjorge et al., 2011) and exposure to necrotic diseases (Fredriksen et al., 2013) and low pH chemicals (Mettam et al., 2012)) thus it is vital that we understand if enrichment can enhance the resilience and recovery from experimentally induced stress and pain to refine experimental protocols. We, therefore used a standard pain test that has been validated and does not cause lasting harm. Previous research has shown subcutaneous injection of acetic acid activates nociceptors in fish (Sneddon et al., 2003a; Ashley et al., 2009) and fish do indeed recover at approximately 3 hours with behaviour and physiology returning to normal (Sneddon, 2003; Sneddon et al., 2003b; a; Reilly et al., 2008a). This allows us to measure recovery from a painful stimulus over a relatively short period of time and prevents longer-term pain or lasting harm to the fish. In this study benzocaine was used over other anaesthetics because it has analgesic properties, has been used in several other studies investigating behaviour and OBR (Sneddon, 2003; Reilly et al., 2008a; Ashley et al., 2009; Mettam et al., 2011), and recovery is reported to be around 10 mins post exposure (Gilderhus and Marking, 1987; Gilderhus, 1989) thus making it appropriate to use for investigating short term responses from stressors. However, benzocaine, a commonly used anaesthestic has been reported to be aversive to zebrafish (Readman et al., 2013) thus the anaesthetic procedure (handling, confinement in the anaesthetic vessel and exposure to a potentially aversive chemical for approximately $10 \mathrm{~min}$ ) and is 
known to be stressful in rainbow trout (Review in Sneddon, 2012). We kept sample sizes to a minimum for statistical analysis and used trout reared for commercial production rather than using a wild species. We believe the benefits of understanding whether enrichment improves recovery in a popular experimental model outweighs the cost of short term pain and stress to a relatively small number of fish used in this study.

Video recordings, each lasting 15 minutes, were made immediately prior to treatment (within 1 minute of treatment) and then at 30 minute intervals post-treatment for three hours using cameras positioned in front of the tanks. During each 15 minute recording period, the opercular beat rate (OBR), a measure of acute stress in fish (Sneddon, 2003; Brown et al., 2005; Reilly et al., 2008a), was recorded. Behavioural video footage was scored blind for total time fish spent immobile (seconds). Immobile behaviour was defined as the fish remaining stationary and showing no visible signs of movement except as a result of maintaining a stationary position within the flow of the water in the tank and also included freezing where the fish appeared to make no movement. Inter-observer reliability tests were conducted between the two observers for behavioural scoring of videos and OBR to ensure repeatability/validity of results.

\subsection{Plasma Sampling}

At the end of the three hour testing period, all fish were humanely killed by concussion followed by pithing at approximately the same time each day $(13: 30 \mathrm{~h} \pm 1 \mathrm{~h})$ to ensure interpretation of plasma cortisol concentrations were not compromised by diel variations in cortisol secretion (Pickering and Pottinger, 1983). Fish were weighed, and blood was collected via sterile heparinised needles (25 g) into $2 \mathrm{ml}$ syringes. After centrifugation at $3500 \mathrm{~g}, 4^{\circ} \mathrm{C}$ for $5 \mathrm{~min}$, the supernatant plasma was frozen and stored at $-20^{\circ} \mathrm{C}$ until further analysis. Cortisol concentrations were determined blind using a validated radioimmunoassay procedure (Pottinger and Carrick, 2001). 


\subsection{Data Analysis}

Change in OBR was compared across time and between treatment and environment using a linear mixed effects model approach (nlme package; Pinheiro et al., 2007), with environment, treatment and time as fixed effects. To account for between-individual variation in initial (pre-treatment) OBR, OBR was analysed as percentage change relative to pre-treatment OBR. To account for repeated measures for each individual fish an additional random effect term of time nested within individual was included. Additionally all interaction terms for all main effects were included in the full model. A model simplification approach was subsequently utilised to determine the minimum adequate model (utilising a Maximum Likelihood approach). An identical process was utilised for the analysis of passive behaviour, which was square root-transformed to meet assumptions of normality and homoscedasticity of the residuals. For OBR the minimum adequate model included all main effects and an interaction of treatment:time, but no further interaction terms; for passive behaviour the minimum adequate model included just the main effects, with no interaction terms. These models were finally analysed using a Restricted Maximum Likelihood approach.

To compare rates of recovery between environments, pre-treatment mean OBR rates for each environment and treatment were tested individually against the post-treatment time points using paired t-tests. It was assumed fish had recovered when pre- and post-treatment time points were no longer significantly different. The recovery OBR rate was estimated by subtracting the mean OBR at the time of recovery from the mean OBR rate at the time point directly following treatment, and divided by the time between time points. This accounted for the variability in recovery rates between individuals. Recovery rates were square root transformed for statistical analysis and a general linear model (GLM) applied using factors of Environment and Treatment.

Plasma cortisol concentrations were square root transformed for statistical analysis, and a GLM used to compare mean plasma cortisol concentration between the factors of Environment and Treatment.

To measure if the relative variability differed between barren and enriched environments, coefficients of variation $(\mathrm{COV})$ were calculated for all measures between environments within treatments. Coefficients of variation are the ratios of the standard deviation to the mean, and are useful for 
comparing the degree of variation between datasets with significantly different means. Finally, a Spearman's rank correlation coefficient was calculated to evaluate the inter observer reliability within the behavioural data. There was a strong significant association between observers within the behavioural scoring data $\left(\mathrm{r}_{\mathrm{s}}=0.968, \mathrm{p}<0.001\right)$.

With the exception of linear mixed effects models, performed in R ( R Version 3.1.1; R Core Team, $\mathrm{R}$ Core Team., 2014), all analyses were performed in Minitab v16 (Minitab, 2009).

\section{Results}

\subsection{Opercular beat rate}

OBR remained level for all fish under control conditions, but those fish under either experimental condition or sham treated was initially elevated immediately post treatment (Fig. 1). In all cases there was a significant decrease in percentage change in OBR, compared to the controls, indicating a return to the pre-treatment condition (Table 1A, Fig. 1). This was slightly more rapid (I.e. a greater coefficient) in the air emersion treatment than the acetic acid and sham treatments. There was a significant main effect of treatment (Table 1A) but, since the interaction of treatment $\mathrm{x}$ time was significant, the main effect itself was ignored.

The interaction between environment and treatment had a significant effect on opercular beat recovery rates $\left(F_{2,46}=7.88, p=0.001\right)$. Recovery rates were faster in an enriched compared with barren environment for both Stress and Sham treatments $(p<0.01)$ but not for the Pain groups $(p=0.752$; Fig. 2).

\subsection{Behaviour}

The main effect of time was significant with a small positive coefficient (Table 1B), indicating that the duration of passive behaviour increased slightly (i.e. the duration of activity decreased) over the course of the experiment following the peak in passive behaviour directly after onset of treatments (Fig. 3). Of the treatments neither acetic acid injection nor air emersion caused any change in passive 
behaviour relative to controls; however, passive behaviour was reduced in the sham treatment relative to controls (Table 1B; Fig. 3). There was no effect of environment on passive behaviour (Table 1B).

\subsection{Cortisol}

Plasma cortisol concentrations three hours after imposition of the stressors were significantly different between treatments $\left(F_{3,64}=13.53, p<0.001\right)$ but no effect of environment was evident for any treatment group (Fig. 4). Fish from the Sham and Pain treatment groups had the highest average cortisol values irrespective of enrichment $\left(15-40 \mathrm{ng} \mathrm{ml}^{-1}\right)$, whereas levels in the Stress and barren Control treatment groups were moderate $\left(5-14 \mathrm{ng} \mathrm{ml}^{-1}\right)$ and the enriched Control treatment exhibited the lowest average cortisol levels $\left(<5 \mathrm{ng} \mathrm{ml}^{-1}\right)$.

\subsection{Coefficients of variation}

The coefficients of variation for each variable were compared between environments (Supplementary Table 1). Inter-individual variation in plasma cortisol concentrations were consistently lower among fish in enriched environments compared to fish held in barren environments.

\section{Discussion}

This study investigated the effects of simple environmental enrichment on the recovery of rainbow trout from stressors and invasive procedures, and the degree of inter-individual variability among the data collected. When exposed to the stress of anaesthesia and handling, and to a standard stressor, fish held in environmentally enriched tanks recovered more quickly than fish held in tanks with no additional ornamentation. In addition, cortisol values were less variable between individuals within the enriched groups. This suggests environmental enrichment does promote recovery following stressful treatments. However, for fish within the groups that received painful stimuli, enrichment had little impact on recovery times and behaviour. This suggests pain is a more aversive stimulus eliciting a stronger response in the fish. Painful stimuli have been shown to be inherently stressful in fish in 
terms of increased plasma cortisol concentrations (Ashley et al., 2009). The differences in responses between painful stimuli and non-painful stressors may be explained by the fact that in teleosts the physiological responses to stress and pain are processed in completely different ways; a stress response activates the hypothalamic-pituitary-interrenal (HPI) axis, whilst painful stimuli have been shown to stimulate the fore- and midbrain areas (Dunlop and Laming, 2005; Nordgreen et al., 2007; Reilly et al., 2008b). Previous studies supporting our findings have also shown that fish exposed to painful stimuli do not respond to novel objects in a normal manner (Sneddon et al., 2003b) and do not exhibit appropriate anti-predator behaviour (Ashley et al., 2009). Thus in this study the severity or intensity of the painful stimulus may override any ameliorating effect provided by enrichment whereas recovery is faster from acute stressors.

Fish held in either environmental conditions did not show any evidence of an increase in activity (suggested non-invasive measure of stress; Huntingford et al., 2006) across the experimental period in any of the treatment groups. If the level of activity can be used as a proxy for stress then earlier studies on zebrafish, Danio rerio (von Krogh et al., 2010) and rainbow trout (Kihslinger and Nevitt, 2006) have both demonstrated a reduction in activity in enriched compared to barren conditions. However, future investigation of other treatments such as exposure to predator cues (Ashley et al., 2009) or other types of painful stimuli may be needed to gauge the importance of environmental enrichment in rainbow trout.

OBR is often used as a non-invasive indicator of stress, and our data illustrate that the fish in all stressor treatment groups exhibited a significant increase in OBR post-treatment compared to control and pre-treatment fish. Similar increases in OBR have been reported in previous studies, in fish exposed to stressors and invasive procedures (Sneddon et al., 2003a; Reilly et al., 2008a; Ashley et al., 2009; Mettam et al., 2011). A difference in OBR between environments was not seen for any treatment group. However, our results did demonstrate the positive impact that environmental enrichment has in speeding up the rate of recovery of fish held in barren conditions compared to those held in enrichment, in response to stressors, but not a painful stimulus. In this case it is not clear as to 
which is the more important indicator of effect; the absolute level of OBR (as shown in Fig. 1) or the rate at which recovery occurs (as shown in Fig. 2), and more work is needed to resolve this issue.

There was no effect of enrichment on cortisol concentrations and this is reflected by other recently published data. For example there was no difference in post-stress plasma cortisol levels in Atlantic salmon held in enriched and barren environments (Naslund et al., 2013). Similarly Wilkes et al. (2012) found no effect of environmental enrichment on zebrafish whole body cortisol concentrations. In contrast however, post-stress whole body cortisol levels were higher in zebrafish held under enriched conditions than those held in barren tanks (von Krogh et al., 2010). We may not have found a difference in our study because of the three hour delay in sampling post-treatment to allow the behaviour and OBR measurements. Post-stress plasma cortisol levels in rainbow trout tend to be greatest approximately $1 \mathrm{hr}$ following an acute stressor and then decline (Pickering and Pottinger, 1989). However, the coefficients of variation for cortisol levels among all treatments was greater for fish held in barren environments than enriched environments, suggesting that enrichment did have some influence on the activity of the HPI axis. Plasma cortisol was elevated in the Sham and Pain group compared with the other groups and may indicate the stress associated with the procedure used in this study (Pounder et al. In prep) including a stress response due to the process of anaesthesia and the actions of the anaesthetic, benzocaine (Review in Sneddon, 2012). However, benzocaine does have analgesic properties whereas many other less aversive drugs would not provide pain-relief during invasive procedures and surgery (e.g. etomidate; Readman et al., 2013).

Evidence presented here implies that the presence or absence of habitat enrichment does not affect the magnitude of inter-individual variation but it does influence recovery rates. The coefficient of variation for cortisol was consistently lower in trout held in enriched environments suggesting that the inter-individual range of HPI responsiveness may be reduced when fish are held under enriched conditions. Cortisol release is particularly affected by stress coping style in rainbow trout so enrichment may go some way to alleviating the confounds of intraspecific variation in stress responsiveness (Thomson et al., 2011; 2012). Therefore the presence of enrichment does appear to 
improve the recovery from stress and reduce physiological variation suggesting that enrichment should be adopted in studies to potentially improve not only the welfare of the fish, but also to enhance the quality of the data. However, caution does need to be applied and any benefits associated with enrichment should be considered on a species by species basis.

Future investigations could explore preference testing, as this would provide an insight into 'what does a fish want?' (Sneddon, 2011), and could enable us to adopt the most appropriate enrichment to assist in improving laboratory fish welfare. For example, preference testing has successfully been demonstrated to determine social (Engeszer et al., 2004), and enrichment preferences in zebrafish (Kistler et al., 2011; Pavlidis et al., 2013; Schroeder et al., 2014). The plasticity of salmonid brains and the impacts of early life experiences have previously been reported (Benowitz and Routtenberg, 1997; Kihslinger and Nevitt, 2006; Ebbesson and Braithwaite, 2012) and so future work could involve rearing fish from hatching under barren versus enriched conditions to see what benefits if any that enrichment provides later in life. In addition, as a common aquaculture species, understanding how simple enrichments such as providing overhead cover improves welfare in laboratory trout (e.g. Pickering et al., 1987) might also be relevant for improving welfare in aquaculture.

The findings of the present study suggest habitat enrichment for rainbow trout may be an important refinement in promoting recovery and ameliorating the adverse effects of stressors. Enrichment did not confound the quality of data but enriched rainbow trout had less variable cortisol values reducing intraspecific differences and possibly improving the quality of the data set. Taken together these results suggest enrichment should be applied to experimental studies using rainbow trout when appropriate and further enrichment should be intelligently considered for other fish species.

\section{Conflict of interest}

Authors declare no conflict of interest 


\section{Acknowledgements}

LS is grateful for a Research Grant (NC/K000888/1) from the National Centre for the 3Rs (NC3Rs)

UK and JM was supported by a Society of Biology Summer Studentship.

\section{References}

R Core Team, 2014. R: A language and environment for statistical computing, R Foundation for Statistical Computing, Vienna, Austria.

Araki, H., Berejikian, B.A., Ford, M.J., Blouin, M.S., 2008. Fitness of hatchery-reared salmonids in the wild. Evol Appl 1, 342-355.

Ashley, P.J., Ringrose, S., Edwards, K.L., Wallington, E., McCrohan, C.R., Sneddon, L.U., 2009. Effect of noxious stimulation upon antipredator responses and dominance status in rainbow trout. Anim Behav 77, 403-410.

Batzina, A., Kalogiannis, D., Dalla, C., Papadopoulou-Daifoti, Z., Chadio, S., Karakatsouli, N., 2014. Blue substrate modifies the time course of stress response in gilthead seabream Sparus aurata. Aquaculture 420, 247-253.

Benowitz, L.I., Routtenberg, A., 1997. GAP-43: An intrinsic determinant of neuronal development and plasticity. Trends Neurosci 20, 84-91.

Bjorge, M.H., Nordgreen, J., Janczak, A.M., Poppe, T., Ranheim, B., Horsberg, T.E., 2011. Behavioural changes following intraperitoneal vaccination in Atlantic salmon (Salmo salar). Appl Anim Behav Sci 133, 127-135.

Braithwaite, V.A., Salvanes, A.G.V., 2005. Environmental variability in the early rearing environment generates behaviourally flexible cod: Implications for rehabilitating wild populations. 272, 1107-1113.

Brown, C., Davidson, T., Laland, K., 2003. Environmental enrichment and prior experience of live prey improve foraging behaviour in hatchery-reared Atlantic salmon. J Fish Biol 63, 187-196. 
Brown, C., Day, R.L., 2002. The future of stock enhancements: lessons for hatchery practice from conservation biology. Fish Fish 3, 79-94.

Brown, C., Gardner, C., Braithwaite, V.A., 2005. Differential stress responses in fish from areas of high- and low-predation pressure. J Comp Physiol B 175, 305-312.

D'Anna, G., Giacalone, V.M., Fernandez, T.V., Vaccaro, A.M., Pipitone, C., Mirto, S., Mazzola, S., Badalamenti, F., 2012. Effects of predator and shelter conditioning on hatchery-reared white seabream Diplodus sargus (L., 1758) released at sea. Aquaculture 356, 91-97.

Dunlop, R., Laming, P., 2005. Mechanoreceptive and nociceptive responses in the central nervous system of goldfish (Carassius auratus) and trout (Oncorhynchus mykiss). J Pain 6, 561-568.

Ebbesson, L.O.E., Braithwaite, V.A., 2012. Environmental effects on fish neural plasticity and cognition. J Fish Biol 81, 2151-2174.

Engeszer, R.E., Ryan, M.J., Parichy, D.M., 2004. Learned social preference in zebrafish. Curr Biol $14,881-884$.

EUDirective, 2010. Directive 2010/63/EU of the European Parliament and of the Council on the protection of animals used for scientific purposes. 22 September 2010.

FEAP, 2014. Production Data.

Fredriksen, B.N., Olsen, R.H., Furevik, A., Souhoka, R.A., Gauthier, D., Brudeseth, B., 2013. Efficacy of a divalent and a multivalent water-in-oil formulated vaccine against a highly virulent strain of Flavobacterium psychrophilum after intramuscular challenge of rainbow trout (Oncorhynchus mykiss). Vaccine 31, 1994-1998.

Frost, A.J., Thomson, J.S., Smith, C., Burton, H.C., Davis, B., Watts, P.C., Sneddon, L.U., 2013. Environmental change alters personality in the rainbow trout, Oncorhynchus mykiss. Anim Behav 85, 1199-1207.

Frost, A.J., Winrow-Giffen, A., Ashley, P.J., Sneddon, L.U., 2007. Plasticity in animal personality traits: does prior experience alter the degree of boldness? P Roy Soc B-Biol Sci 274, 333339.

Gilderhus, P.A., 1989. Efficacy of Benzocaine as an Anaesthetic for Salmonid Fishes. N Am J Fish Manage 9, 150-153. 
Gilderhus, P.A., Marking, L.L., 1987. Comparative Efficacy of 16 Anesthetic Chemicals on Rainbow Trout. N Am J Fish Manage 7, 288-292.

Gilmour, K.M., DiBattista, J.D., Thomas, J.B., 2005. Physiological causes and consequences of social status in salmonid fish. Integr Comp Biol 45, 263-273.

Hansen, T.J., Moller, D., 1985. Yolk Absorption, Yolk-Sac Constrictions, Mortality, and Growth during 1st Feeding of Atlantic Salmon (Salmo salar) Incubated on Astro-Turf. Can J Fish Aquat Sci 42, 1073-1078.

HomeOffice, 2013. Annual Statistics of Scientific Procedures on Living Animals Great Britain 2013.

Huntingford, F.A., 2004. Implications of domestication and rearing conditions for the behaviour of cultivated fishes. J Fish Biol 65, 122-142.

Huntingford, F.A., Adams, C., Braithwaite, V.A., Kadri, S., Pottinger, T.G., Sandoe, P., Turnbull, J.F., 2006. Current issues in fish welfare. J Fish Biol 68, 332-372.

Kellison, G.T., Eggleston, D.B., Burke, J.S., 2000. Comparative behaviour and survival of hatchery reared versus wild summer flounder (Paralichthys dentatus). Can J Fish Aquat Sci 57, 18701877.

Kihslinger, R.L., Nevitt, G.A., 2006. Early rearing environment impacts cerebellar growth in juvenile salmon. J Exp Biol 209, 504-509.

Killen, S.S., Marras, S., Metcalfe, N.B., McKenzie, D.J., Domenici, P., 2013. Environmental stressors alter relationships between physiology and behaviour. Trends Ecol Evol 28, 651-658.

Kistler, C., Hegglin, D., Wurbel, H., Konig, B., 2011. Preference for structured environment in zebrafish (Danio rerio) and checker barbs (Puntius oligolepis). Appl Anim Behav Sci 135, 318327.

Leon, K.A., 1975. Improved Growth and Survival of Juvenile Atlantic Salmon (Salmo salar) Hatched in Drums Packed with a Labyrinthine Plastic Substrate. Prog Fish Cult 37, 158-163.

Marchetti, M.P., Nevitt, G.A., 2003. Effects of hatchery rearing on brain structures of rainbow trout, Oncorhynchus mykiss. Environ Biol Fish 66, 9-14. 
Mettam, J.J., McCrohan, C.R., Sneddon, L.U., 2012. Characterisation of chemosensory trigeminal receptors in the rainbow trout, Oncorhynchus mykiss: Responses to chemical irritants and carbon dioxide. 215, 685-693.

Mettam, J.J., Oulton, L.J., McCrohan, C.R., Sneddon, L.U., 2011. The efficacy of three types of analgesic drugs in reducing pain in the rainbow trout, Oncorhynchus mykiss. Appl Anim Behav Sci 133, 265-274.

Minitab, I., 2009. Minitab Statistical Software, Release 16 for windows, State College, Pennsylvania. Minitab® is a registered trademark of Minitab, Inc.

Näslund, J., Johnsson, J.I., 2014. Environmental enrichment for fish in captive environments: Effects of physical structures and substrates. Fish Fish.

Naslund, J., Rosengren, M., Del Villar, D., Gansel, L., Norrgard, J.R., Persson, L., Winkowski, J.J., Kvingedal, E., 2013. Hatchery tank enrichment affects cortisol levels and shelter-seeking in Atlantic salmon (Salmo salar). Can J Fish Aquat Sci 70, 585-590.

Nordgreen, J., Horsberg, T.E., Ranheim, B., Chen, A.C.N., 2007. Somatosensory evoked potentials in the telencephalon of Atlantic salmon (Salmo salar) following galvanic stimulation of the tail. $\mathrm{J}$ Comp Physiol A 193, 1235-1242.

Pavlidis, M., Digka, N., Theodoridi, A., Campo, A., Barsakis, K., Skouradakis, G., Samaras, A., Tsalafouta, A., 2013. Husbandry of Zebrafish, Danio rerio, and the Cortisol Stress Response. Zebrafish 10, 524-531.

Pickering, A.D., Griffiths, R., Pottinger, T.G., 1987. A Comparison of the Effects of Overhead Cover on the Growth, Survival and Hematology of Juvenile Atlantic Salmon, Salmo salar L, Brown Trout, Salmo trutta L, and Rainbow Trout, Salmo gairdneri Richardson. Aquaculture 66, 109124.

Pickering, A.D., Pottinger, T.G., 1983. Seasonal and diel changes in plasma cortisol levels of the brown trout, Salmo trutta L. Gen Comp Endocr 49, 232-239.

Pickering, A.D., Pottinger, T.G., 1989. Stress Responses and Disease Resistance in Salmonid Fish Effects of Chronic Elevation of Plasma Cortisol. Fish Physiol Biochem 7, 253-258. 
Pinheiro, J., Bates, D., DebRoy, S., Sarkar, D., 2007. Linear and nonlinear mixed effects models. R package version 3,57 .

Pottinger, T.G., Carrick, T.R., 2001. Stress responsiveness affects dominant-subordinate relationships in rainbow trout. Horm Behav 40, 419-427.

Readman, G.D., Owen, S.F., Murrell, J.C., Knowles, T.G., 2013. Do Fish Perceive Anaesthetics as Aversive? Plos One 8.

Reilly, S.C., Quinn, J.P., Cossins, A.R., Sneddon, L.U., 2008a. Behavioural analysis of a nociceptive event in fish: Comparisons between three species demonstrate. Appl Anim Behav Sci 114, 248259.

Reilly, S.C., Quinn, J.P., Cossins, A.R., Sneddon, L.U., 2008b. Novel candidate genes identified in the brain during nociception in common carp (Cyprinus carpio) and rainbow trout (Oncorhynchus mykiss). Neurosci Lett 437, 135-138.

Rodewald, P., Hyvarinen, P., Hirvonen, H., 2011. Wild origin and enriched environment promote foraging rate and learning to forage on natural prey of captive reared Atlantic salmon parr. Ecol Freshw Fish 20, 569-579.

Salvanes, A.G.V., Moberg, O., Ebbesson, L.O.E., Nilsen, T.O., Jensen, K.H., Braithwaite, V.A., 2013. Environmental enrichment promotes neural plasticity and cognitive ability in fish. P Roy Soc B-Biol Sci 280.

Schroeder, P., Jones, S., Young, I.S., Sneddon, L.U., 2014. What do zebrafish want? Impact of social grouping, dominance and gender on preference for enrichment. Lab Anim-Uk 48, 328-337.

Simpson, J., Kelly, J.P., 2011. The impact of environmental enrichment in laboratory rats-Behavioural and neurochemical aspects. Behav Brain Res 222, 246-264.

Singhal, G., Jaehne, E.J., Corrigan, F., Baune, B.T., 2014. Cellular and molecular mechanisms of immunomodulation in the brain through environmental enrichment. Front Cell Neurosci 8.

Sneddon, L.U., 2003. The evidence for pain in fish: the use of morphine as an analgesic. Appl Anim Behav Sci 83, 153-162.

Sneddon, L.U., 2011. Cognition and Welfare, in: Brown, C., Laland, K., Krause, J. (Eds.), Fish Cognition and Behaviour, Wiley-Blackwell, pp. 405-434. 
Sneddon, L.U., 2012. Clinical Anesthesia and Analgesia in Fish. J Exot Pet Med 21, 32-43.

Sneddon, L.U., Braithwaite, V.A., Gentle, M.J., 2003a. Do fishes have nociceptors? Evidence for the evolution of a vertebrate sensory system. P Roy Soc B-Biol Sci 270, 1115-1121.

Sneddon, L.U., Braithwaite, V.A., Gentle, M.J., 2003b. Novel object test: Examining nociception and fear in the rainbow trout. J Pain 4, 431-440.

Sneddon, L.U., Schmidt, R., Fang, Y.X., Cossins, A.R., 2011. Molecular Correlates of Social Dominance: A Novel Role for Ependymin in Aggression. Plos One 6.

Strand, D.A., Utne-Palm, A.C., Jakobsen, P.J., Braithwaite, V.A., Jensen, K.H., Salvanes, A.G.V., 2010. Enrichment promotes learning in fish. Mar Ecol Prog Ser 412, 273-282.

Sundstrom, L.F., Petersson, E., Hojesjo, J., Johnsson, J.I., Jarvi, T., 2004. Hatchery selection promotes boldness in newly hatched brown trout (Salmo trutta): implications for dominance. Behav Ecol 15, 192-198.

Thomson, J.S., Watts, P.C., Pottinger, T.G., Sneddon, L.U., 2011. Physiological and genetic correlates of boldness: Characterising the mechanisms of behavioural variation in rainbow trout, Oncorhynchus mykiss. Horm Behav 59, 67-74.

Thomson, J.S., Watts, P.C., Pottinger, T.G., Sneddon, L.U., 2012. Plasticity of boldness in rainbow trout, Oncorhynchus mykiss: do hunger and predation influence risk-taking behaviour? Horm Behav 61, 750-757.

Thorgaard, G.H., Bailey, G.S., Williams, D., Buhler, D.R., Kaattari, S.L., Ristow, S.S., Hansen, J.D., Winton, J.R., Bartholomew, J.L., Nagler, J.J., Walsh, P.J., Vijayan, M.M., Devlin, R.H., Hardy, R.W., Overturf, K.E., Young, W.P., Robison, B.D., Rexroad, C., Palti, Y., 2002. Status and opportunities for genomics research with rainbow trout. Comp Biochem Phys B 133, 609-646. von Krogh, K., Sorensen, C., Nilsson, G.E., Overli, O., 2010. Forebrain cell proliferation, behavior, and physiology of zebrafish, Danio rerio, kept in enriched or barren environments. Physiol

Behav 101, 32-39.

Weigel, D.E., Connolly, P.J., Powell, M.S., 2014. Fluvial rainbow trout contribute to the colonization of steelhead (Oncorhynchus mykiss) in a small stream. Environ Biol Fish 97, 1149-1159. 
Wilkes, L., Owen, S.F., Readman, G.D., Sloman, K.A., Wilson, R.W., 2012. Does structural 512 enrichment for toxicology studies improve zebrafish welfare? Appl Anim Behav Sci 139, 143150.

Williams, T.D., Readman, G.D., Owen, S.F., 2009. Key issues concerning environmental enrichment for laboratory-held fish species. Lab Anim-Uk 43, 107-120. 
Figure 1. Mean (+SE) change in opercular beat rate $(\mathrm{OBR} ; \%)$ in rainbow trout held under either enriched (open symbols) or barren (closed symbols) environments, over the experimental period of 3 520 hrs. Measurements were taken at 30 minute intervals ( $\mathrm{n}=8$ per group).

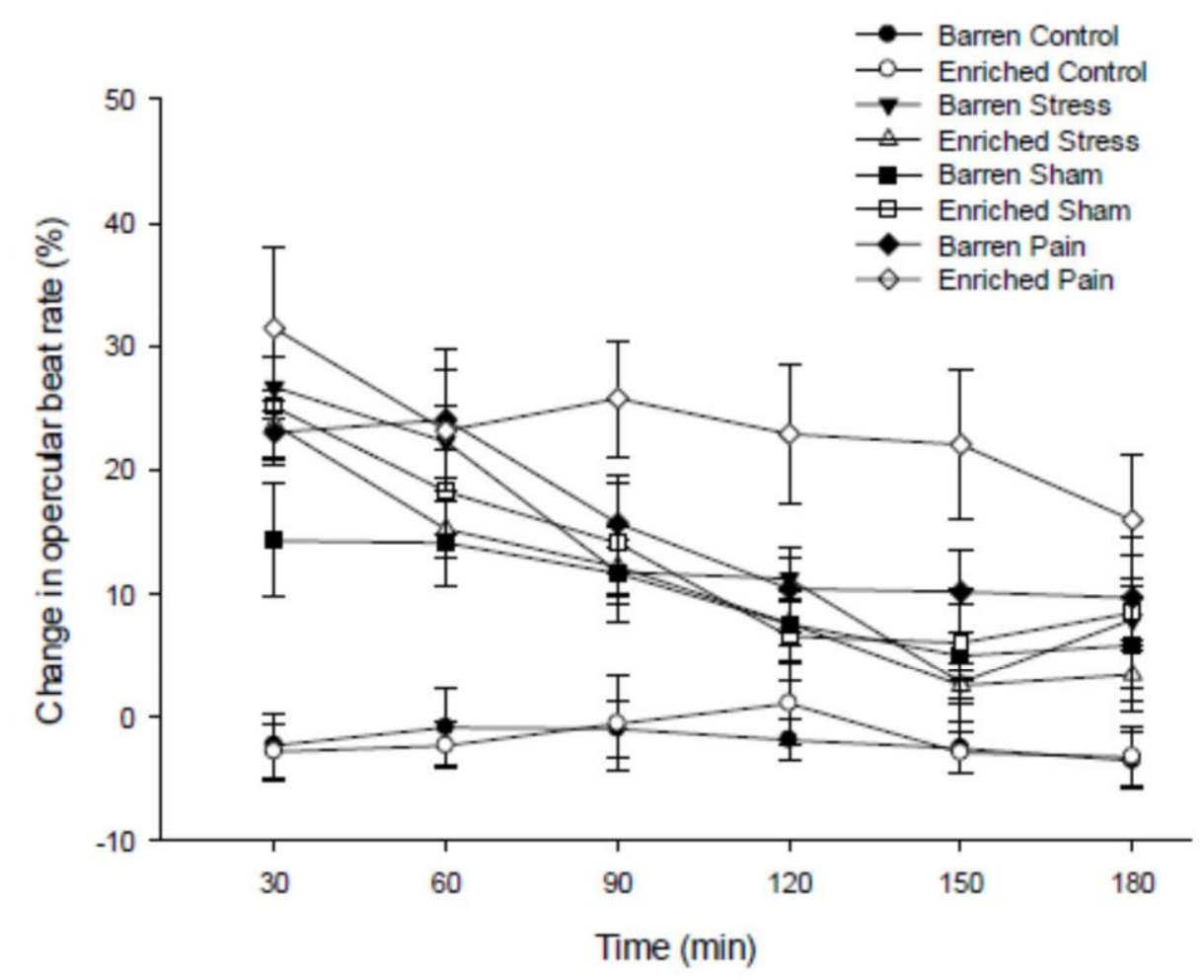


Figure 2. Mean (+SE) opercular beat recovery rate (beats $\mathrm{min}^{-1}$ ) post treatment, in rainbow trout held under either enriched (white bars) or barren (black bars) environments. Recovery OBR rate was estimated for each individual fish by subtracting OBR at time of recovery from OBR rate at first time point post treatment, and divided by the time between time points: 150 minutes for Stress (enriched and barren) and Sham (barren), 120 mins for Sham (enriched), and 180 mins for Pain (enriched and barren) ( $\mathrm{n}=8$ per group; general linear model). Displayed $p$ value denotes significant difference between environments.

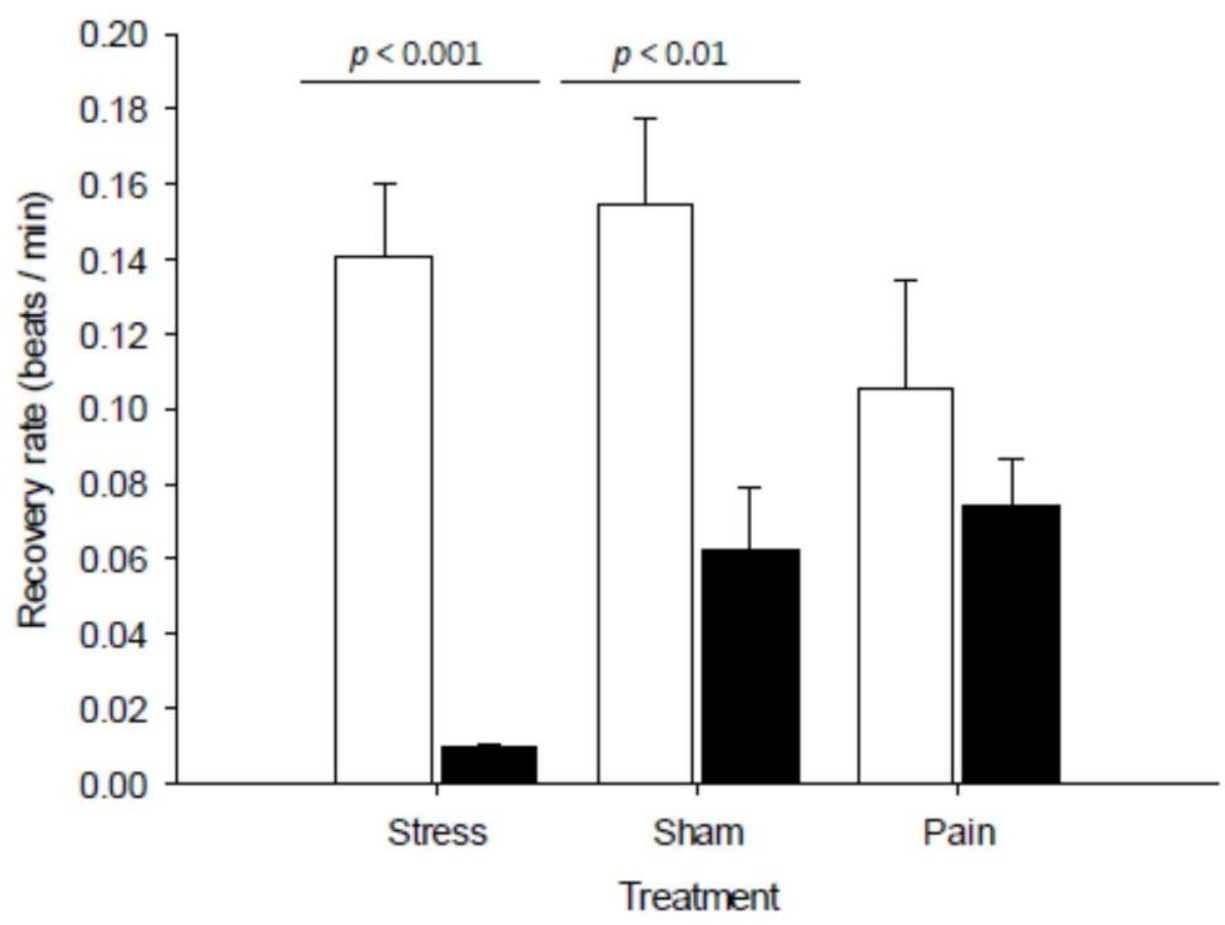


Figure 3. Mean $( \pm$ SE) change in total time spent passive $(\%)$ in rainbow trout held under either enriched (open symbols) or barren (closed symbols) environments, over the experimental period of $3 \mathrm{hrs}$. Measurements were taken at 30 minute intervals ( $n=8$ per group).

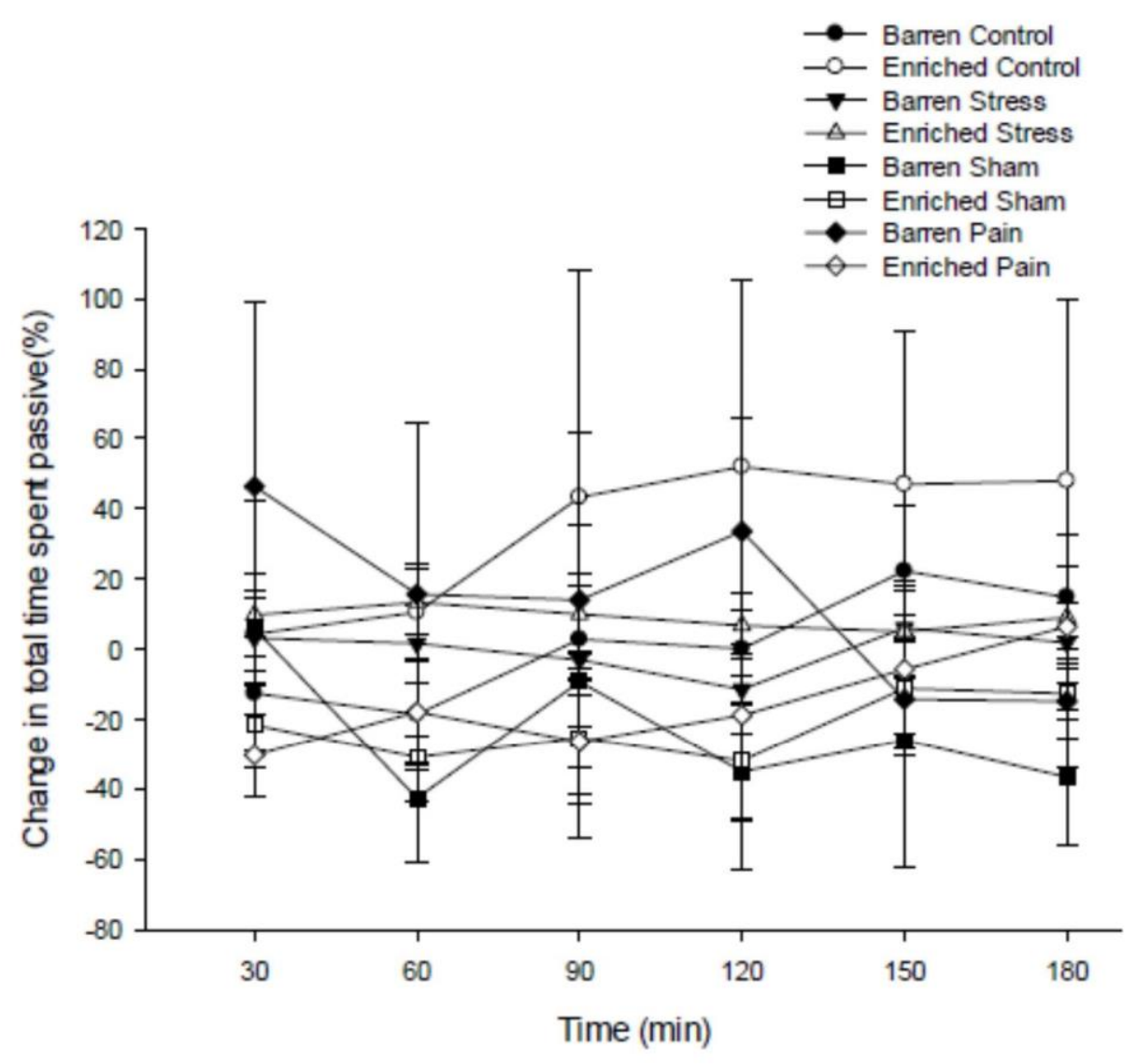


Figure 4. Mean (+SE) plasma cortisol concentrations $\left(\mathrm{ng} \mathrm{ml}^{-1}\right)$ three hours post treatment, in rainbow trout held under either enriched (white bars) or barren (black bars) environments $\left(F_{1,64}=1.49, \mathrm{p}=\right.$ $0.227 ; \mathrm{n}=8$ per group; general linear model).

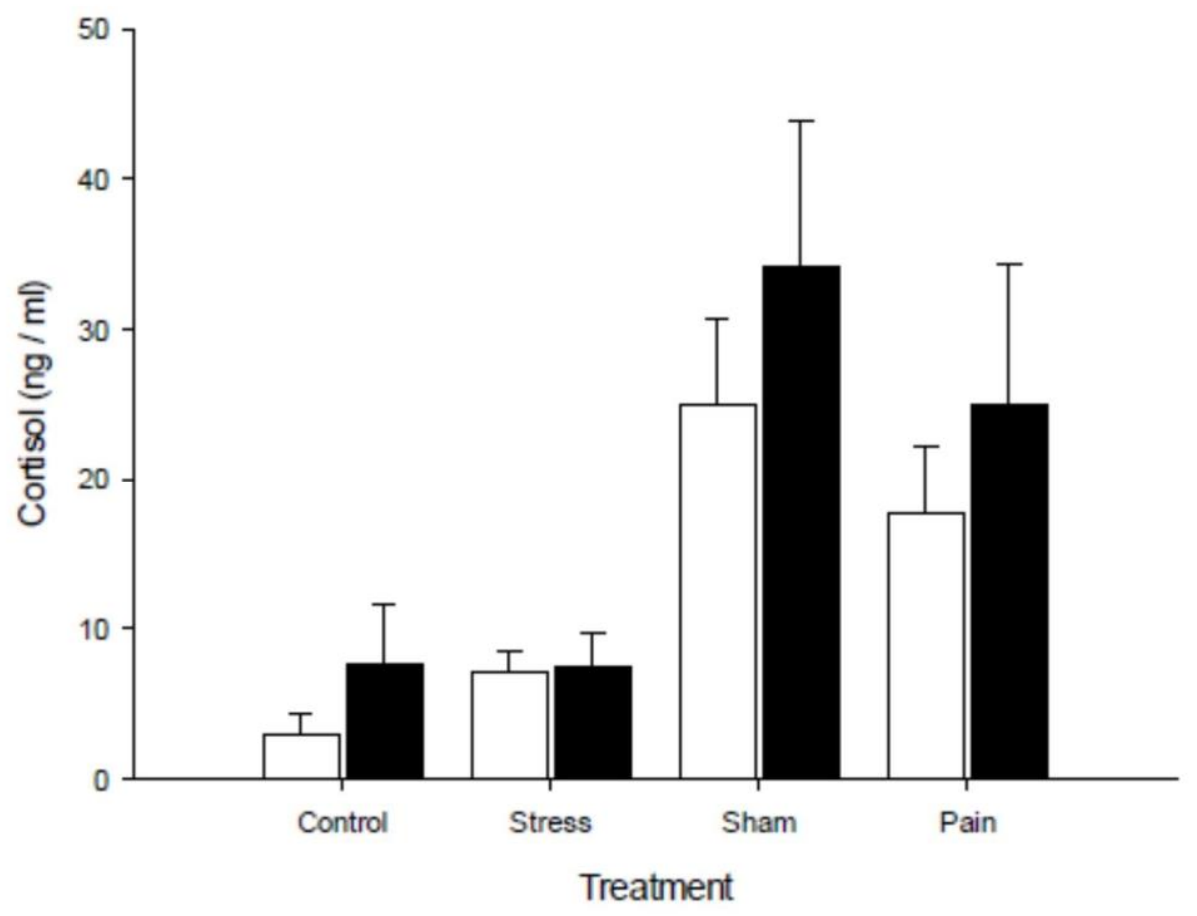


Table 1. Coefficient estimates $( \pm \mathrm{SE})$ with associated $t$ and $p$ values for all terms retained in the minimum adequate model for (A) opercular beat rate and (B) square-root transformed duration of passive behaviour. Significant terms are in bold.

\section{A: Opercular Beat Rate}

\begin{tabular}{|c|c|c|c|c|c|}
\hline Predictor & & Coefficient & S.E. & $t$ & $p$ \\
\hline Intercept & & 97.44 & 2.60 & 37.52 & $<0.0005$ \\
\hline Environment & Enriched & 2.10 & 2.16 & 0.97 & 0.335 \\
\hline \multirow[t]{3}{*}{ Treatment } & Acetic Acid & 28.06 & 3.34 & 8.41 & $<0.0005$ \\
\hline & Air Emersion & 24.45 & 3.34 & 7.33 & $<0.0005$ \\
\hline & Sham & 20.07 & 3.34 & 6.02 & $<0.0005$ \\
\hline Time & & -0.007 & 0.01 & -0.56 & 0.576 \\
\hline \multirow[t]{3}{*}{ Interactions } & Time x Acetic Acid & -0.09 & 0.02 & -4.89 & $<0.0005$ \\
\hline & Time $\mathrm{x}$ Air Emersion & -0.13 & 0.02 & -7.47 & $<0.0005$ \\
\hline & Time x Sham & -0.09 & 0.02 & -5.00 & $<0.0005$ \\
\hline
\end{tabular}

\section{B: Passive Behaviour}

\begin{tabular}{llcccc}
\hline \multicolumn{1}{c}{ Predictor } & & Coefficient & S.E. & $\boldsymbol{t}$ & $\boldsymbol{p}$ \\
\hline Intercept & & 9.85 & 0.90 & $\mathbf{1 0 . 9 8}$ & $<\mathbf{0 . 0 0 0 5}$ \\
Environment & Enriched & 0.36 & 0.79 & 0.45 & 0.653 \\
Treatment & Acetic Acid & -0.98 & 1.12 & -0.87 & 0.386 \\
& Air Emersion & -0.29 & 1.12 & -0.26 & 0.798 \\
& Sham & -2.65 & 1.12 & $\mathbf{- 2 . 3 7}$ & $\mathbf{0 . 0 2 1}$ \\
\multirow{2}{*}{ Time } & & 0.004 & 0.002 & $\mathbf{1 . 9 8}$ & $\mathbf{0 . 0 4 9}$ \\
\hline
\end{tabular}


